\title{
O PROCESSO DE INTERAÇÃO EM TORNO DO FEEDBACK CORRETIVO ORAL E A TEORIA SOCIOCULTURAL NO ENSINO DE INGLÊS COMO LÍNGUA ESTRANGEIRA
}

\section{THE INTERACTION REGARDING THE ORAL CORRECTIVE FEEDBACK AND THE SOCIOCULTURAL THEORY IN TEACHING ENGLISH AS A FOREIGN LANGUAGE}

\author{
Tarsila Rubin Battistella ${ }^{1}$ \\ Instituto Federal do Rio Grande do Sul \\ Marilia dos Santos Lima ${ }^{2}$ \\ Universidade do Vale do Rio dos Sinos
}

\begin{abstract}
RESUMO
O objetivo deste artigo é trazer algumas reflexões sobre o processo de ensino-aprendizagem de inglês como língua estrangeira (LE), a partir da interação em torno do feedback corretivo oral e de conceitos da teoria sociocultural, focalizando os aprendizes e a professora de um curso de Licenciatura em Letras/Inglês em uma universidade privada no sul do Brasil. Os resultados apontam que a correção é significativa no sentido de promover o ensino-aprendizagem de uma LE, ao ser realizada levando-se em consideração fatores linguísticos, cognitivos e idiossincráticos dos aprendizes. Percebemos que o feedback corretivo e a aprendizagem da língua podem ser beneficiados pela mediação linguística e pela interação dialógica entre os envolvidos no processo.
\end{abstract}

PALAVRAS-CHAVE: feedback corretivo oral; teoria sociocultural; dynamic assessment, língua estrangeira.

\section{ABSTRACT}

The aim of this paper is to reflect on the teaching and learning process of English as a Foreign Language (FL) through the interaction regarding the corrective feedback and the sociocultural theory concepts, with focus on the learners and the teacher of an English Teacher Education Course in a private university in the south of Brazil. The results show that feedback is important in promoting FL learning, taking into account learners' linguistic, cognitive and idiosyncratic factors. It was observed that language mediation and dialogic interaction by the research participants were beneficial to corrective feedback and language learning.

KEYWORDS: oral corrective feedback; sociocultural theory; dynamic assessment; foreign language.

\footnotetext{
${ }^{1}$ Doutora em Linguística Aplicada pela Universidade do Vale dos Sinos. E-mail: tarsilabattistella@yahoo.com.br

${ }^{2}$ Doutora em Linguística Aplicada pela University of Reading. E-mail: marilim@unisinos.br
} 


\section{INTRODUÇÃO}

Ao relacionarmos o erro com a aprendizagem, definida pela teoria vygotskiana (VYGOTSKY, 1978; 1986) como um fenômeno social e pertinente ao contexto histórico e cultural dos indivíduos, adotamos uma visão mais híbrida da pedagogia, que combina os princípios da teoria sociocultural com outros paradigmas, tais como o feedback corretivo e o dynamic assessment no ensino-aprendizagem de LE. Consideramos que essa visão do feedback corretivo, pelo viés da teoria sociocultural, pode significar um avanço na visão do erro, dado que a sua eficácia nesse processo depende da maneira como o feedback corretivo está inserido na interação e de como ele é negociado entre os participantes no ensino-aprendizagem de LE (NASSAJI; SWAIN, 2000).

Assim, partimos da premissa de que o conhecimento é construído socialmente e que o feedback fornecido na interação pode facilitar o progresso do aprendiz e contribuir para a sua formação como professor de LE. Destacamos também aqui a necessidade de conceber a aprendizagem como propulsora do desenvolvimento do aprendiz, cuja LE é vista como um instrumento mediador para o desenvolvimento do indivíduo (LANTOLF; POEHNER, 2008).

Neste artigo, propomos ampliar a discussão na área de ensino-aprendizagem de línguas, ao investigar o processo de aprendizagem de inglês como LE no ambiente universitário de formação de professores, contribuindo para uma melhor compreensão do processo corretivo em sala de aula de LE. Nessa perspectiva, este trabalho foi norteado pelas seguintes questões: quais tipos de correção referentes à produção oral dos aprendizes são providas aos alunos pela professora? Como o feedback corretivo se relaciona ao processo de ensino-aprendizagem dos alunos?

Em um primeiro momento, este artigo apresenta um breve estado da arte acerca da teoria sociocultural, incluindo o dynamic assesssment (DA), além do ensino de línguas fundamentado no feedback corretivo oral. Em seguida, apresentamos os procedimentos metodológicos utilizados para realizar a pesquisa. Evidenciamos os principais resultados, incluindo amostras dos dados representativos, a partir do arcabouço teórico apresentado. Finalmente, tecemos algumas considerações, discutindo os resultados da pesquisa e seus possíveis impactos para o ensino de línguas estrangeiras.

\section{Fundamentos da teoria sociocultural e o conceito de dynamic assessment}

A teoria sociocultural caracteriza os aspectos do comportamento humano, e sugere que o desenvolvimento depende da interação do indivíduo com as pessoas e com as ferramentas que a cultura oferece ao longo da história humana, para que ele possa formar a sua própria visão de mundo e evoluir (VYGOTSKY, 1978; 1986).

Essa perspectiva percebe a linguagem como prática social, enfatizando a relação entre a aprendizagem e o papel do conhecimento construído socialmente, ou seja, ela visa a entender o desenvolvimento cognitivo do indivíduo a partir da interação dele com o meio. Nesse caso, os significados são construídos e remodelados através da mediação social (VYGOTSKY, 1978).

A noção de mediação da linguagem implica que os indivíduos não agem diretamente no mundo, não obstante, contam com o suporte de artefatos materiais (tecnologia, dicionário, livro) ou simbólicos (linguagem), que permitem que o mundo mude através da ação dos mesmos (WERTSCH, 2007). Lantolf e Thorne (2006) afirmam que os artefatos são aqueles aspectos materiais e conceituais que caracterizam e constituem as atividades humanas. Nesse sentido, tomamos a linguagem como sendo o principal canal de mediação (MITCHELL; 
MYLES; MARDSEN, 2013) disponível aos indivíduos participantes da interação social, no sentido de que a aprendizagem, o crescimento intelectual e o conhecimento humano estão intermentalmente pautados às relações sociais.

A partir disso, o conhecimento coconstruído passa de um nível intermental (aquele partilhado entre as pessoas) para o nível intramental (individual), em um processo de internalização em que ocorre uma reconstrução interna, por meio da qual, posteriormente, o indivíduo passará a realizar novas operações externas.

$\mathrm{Na}$ teoria sociocultural, os aprendizes são vistos como coconstrutores do seu próprio conhecimento, dado que a aprendizagem é percebida como socialmente situada, colaborativa e como um processo mutuamente benéfico, de transformação acadêmica e social (HALL, 2001).

$\mathrm{O}$ estudos de Vygotsky ainda explicam que a relação entre a aprendizagem e o desenvolvimento do aprendiz pode ser beneficiada pela sua zona de desenvolvimento proximal - ZDP (VYGOTSKY, 1978). A ZDP é definida como a diferença entre o nível de desenvolvimento real, determinado pela resolução de problemas individuais e o nível de desenvolvimento potencial, determinado por meio da solução de problemas, mediado pela colaboração do professor ou de pessoas mais experientes (VYGOTSKY, 1986).

No contexto de sala de aula, Hall (2001) caracteriza a ZDP como um local dinâmico de aprendizagem que está entre os aprendizes, isto é, está na interação e na assistência efetiva entre o aprendiz e o seu colega para que se chegue a um entendimento comum ou à realização de uma tarefa. Nada mais é do que o domínio onde a aprendizagem pode ser mais produtiva, que se desdobra por meio da interação, expandindo o potencial de aprendizagem, ou seja, na ZDP, a aprendizagem induz ao desenvolvimento (SWAIN; KINNEAR; STEINMANN, 2011).

A ZDP é um conceito chave para explicar o feedback corretivo (ELLIS, 2009), visto que ele pode ser aceito como um meio de estudar como a interaçáo medeia a aprendizagem atraves da coconstrução de ZDPs. Assim, o feedback é uma atividade de ação colaborativa, social e dialógica, que envolve a participação significativa de troca de experiências e conhecimentos entre as pessoas (NASSAJI; SWAIN, 2000).

O dynamic assessment (DA) foi introduzido como um modo de avaliar, fundamentado na teoria sociocultural e na ZDP vygotskiana, considerando-se que as habilidades dos aprendizes são dinâmicas e resultantes da interação social do indivíduo no e com o mundo. Lantolf e Poehner (2011) definem DA como o processo de documentar o conhecimento, habilidades, atitudes e crenças ou ainda a compreensão das habilidades atuais de uma pessoa. Luria (1961) foi supostamente um dos primeiros a propor uma visão um pouco mais sistemática dessa abordagem, em oposição aos procedimentos estáticos que avaliam o conhecimento do indivíduo de modo isolado e os resultados da aprendizagem retroativamente.

Em linhas gerais, o DA originou-se da observação de que os aprendizes com níveis de desenvolvimento semelhantes podem realizar a mesma atividade de modo distinto quando lhes é fornecido algum tipo de assistência processual em sala de aula. Ao fornecer auxílio apropriado ao aprendiz, com o uso de prompts, pistas metalinguísticas e perguntas indutivas (LANTOLF; THORNE, 2006), o mediador promove o desenvolvimento do mesmo, ao passo em que acessa as habilidades desse aprendiz (DAVIN, 2013) por meio da instrução e da avaliação graduada e contingente.

Logo, podemos afirmar que o objetivo do DA é medir as habilidades linguísticas, intervir na aprendizagem e documentar o crescimento dos aprendizes, auxiliando os professores no entendimento daquilo que o indivíduo necessita e quais são os passos para apoiar a aprendizagem futura de modo interativo e dialógico (BODROVA; LEONG, 2007). 
Por se tratar de uma abordagem direcionada para o futuro, o foco do DA está no processo de desenvolvimento do aprendiz, visto que o mediador o auxilia a chegar à resposta exata por meio da mediação (do nível mais implícito para o mais explícito) e não do fornecimento imediato da resposta correta a ele. Nesse caso, enfatizamos que o DA integra a avaliação e a instrução como uma atividade baseada na ZDP (POEHNER, 2009), que procura diagnosticar e promover o desenvolvimento do aluno simultaneamente, oferecendo mediação aos aprendizes (PANAHI; BIRJANDI; AZBDAFTARI, 2013).

Levando em consideração o que foi exposto, pode-se afirmar que as técnicas do DA fornecem aos aprendizes experiências de aprendizagem mediada (mediated learning experience, (LIDZ, 1991), que são filtradas e interpretadas de acordo com a necessidade de cada um, por meio da interação social.

Ao relacionar o DA ao ensino-aprendizagem de línguas, acreditamos que a qualidade e o tipo de mediação fornecida aos aprendizes são essenciais para promover o desenvolvimento na língua-alvo, visto que se pretende interpretar corretamente e auxiliar os aprendizes a expandir seus potenciais de aprendizagem (LANTOLF; POEHNER, 2004). Sendo assim, o DA apresenta uma interface com o feedback corretivo no que tange à negociação de sentidos, mediação e trocas linguísticas entre os participantes da interação no ensino-aprendizagem de línguas, como exposto na sequência.

\section{O feedback corretivo oral no ensino de línguas}

O processo corretivo tem causado algumas inquietações para pesquisadores e professores no que tange à maneira de ser abordado em sala de aula, levantando questões sobre como corrigir, por que corrigir, quais erros corrigir e quando corrigir (LYSTER; RANTA, 1997).

Segundo Ellis (2009), o feedback corretivo pode ser definido como um tipo de feedback no qual se focaliza a fala do aprendiz que contém um erro linguístico, sendo que o professor evidencia de alguma maneira que há uma inadequação na fala. Ao sinalizar a inadequação, o professor procura direcionar a atenção do aprendiz à sua produção, envolvendo-o em um trabalho interativo que pode resultar em modificações capazes de auxiliar o aluno na aprendizagem da LE (BORBA, LIMA, 2004). Ao receber o feedback, o aprendiz poderá reformular seus enunciados para ser melhor compreendido na interação com seus pares.

Um dos estudos amplamente citados nessa área é o de Lyster e Ranta (1997), que procurou responder à pergunta sobre como o professor corrige, a partir da categorização de seis diferentes tipos de feedback corretivo. Os pesquisadores observaram os tipos de feedback corretivo decorrentes de atividades comunicativas (orais) com seus aprendizes, no Canadá. Ao analisarem os dados, eles encontraram seis diferentes tipos de feedback corretivo, a saber: a correção explícita, os recasts, os pedidos de esclarecimento, o feedback metalinguístico, a elicitação e a repetição.

Posteriormente, a partir de estudos de Ranta e Lyster (2007) e de Lyster (2001; 2004), os tipos de feedback corretivo foram classificados em duas categorias mais abrangentes: as reformulações e os prompts. As reformulações abarcam os recasts e a correção explícita, porque ambas fornecem algum tipo de modificação à produção errônea do aprendiz, ou seja, o próprio professor faz a correção. Os prompts, por sua vez, englobam a elicitação, pistas metalinguísticas, pedidos de esclarecimento e a repetição. Por meio dos prompts, o professor fornece pistas para que o aluno reformule o seu próprio enunciado, o que faz com que a interação em sala de aula seja mais dinâmica e motivadora. 
Acreditamos que o processo corretivo na sala de aula é parte central das questões interacionais que possibilitam que os aprendizes saibam quais são os critérios de seu desempenho que estão sendo avaliados, e possam cotejar suas atitudes a esses critérios específicos (HALL, 2001), estando relacionado aos princípios socioculturais.

Um dos estudos que estabelecem uma relação entre a teoria sociocultural e o feedback corretivo no ensino de línguas é o estudo de Nassaji e Swain (2000). Na pesquisa, os autores avaliaram se o feedback fornecido dentro da ZDP do aprendiz poderia ampliar o seu conhecimento sobre os artigos em inglês, em oposição ao feedback aleatório, sem levar em consideração a ZDP do aluno. Os pesquisadores realizaram o estudo de caso com duas alunas de inglês como L2 e falantes nativas de coreano, em um curso de escrita na língua-alvo de uma universidade do Canadá. Eles avaliaram a assistência que era fornecida pelo tutor para os seus erros escritos acerca do uso dos artigos definidos e indefinidos do inglês, seguindo os princípios da escala regulatória de Aljaafreh e Lantolf (1994), que prevê a correção do nível mais implícito para o explícito, e o feedback aleatorio.

Foram realizadas quatro sessões de correção, de aproximadamente 40 minutos cada, nas quais os textos escritos pelas alunas eram corrigidos pelos tutores. As sessões aconteceram uma vez por semana, foram gravadas em áudio, transcritas e analisadas. A análise dos dados evidenciou que o apoio colaborativo na ZDP do aprendiz foi mais eficaz do que a ajuda aleatoria, revelando uma diferença no desempenho dos aprendizes dentro e fora da ZDP. Os dados sugerem também que a aluna que recebeu o feedback corretivo dentro da ZDP teve um aprendizado progressivo e melhor do que a outra que não recebeu o apoio interativo e colaborativo do tutor.

A partir do estudo de Nassaji e Swain (2000), entendemos que o feedback corretivo fornecido dentro da ZDP do aprendiz, mediando a relação dele com a linguagem, mostra-se mais eficaz e está relacionado intrinsecamente à teoria sociocultural, na qual o conhecimento é construído por meio de um processo de colaboração, interaçáa e comunicação entre os alunos e o professor. A quantidade e a qualidade do feedback provido pelo professor também são relevantes para que a ZDP seja coconstruída com os aprendizes. Assim, o erro reflete o processamento linguístico e o desenvolvimento cognitivo do aprendiz. Dentro desse contexto, o professor precisa saber qual o momento oportuno para corrigir o aluno, fazendo o uso de diferentes estratégias a fim de que a correção envolva os aprendizes na troca, na construção do conhecimento (HALL, 2001) e esteja a favor da aprendizagem da LE.

\section{A metodologia do estudo desenvolvido}

A presente pesquisa caracteriza-se como uma pesquisa qualitativa, de cunho interpretativista (BURNS, 1999), e enfoca um contexto universitário de um curso de Licenciatura em Letras/Inglês, com duração de quatro anos e regime semestral de aulas, de uma universidade privada do Rio Grande do Sul.

O quadro metodológico interpretativo (ERICKSON, 1986) permite o uso de métodos qualitativos e o envolvimento do pesquisador na investigação. Assim, o estudo tem caráter êmico e foi constituído por meio de análise qualitativa dos dados.

Os dados para esta pesquisa foram coletados ao longo de um semestre da disciplina de Inglês $\mathrm{V}$ (nível pré-intermediário a intermediário de inglês), em treze encontros, de um total de quinze encontros. Como instrumentos de coleta de dados foram utilizadas narrativas escritas, gravação em áudio e vídeo (15 horas disponibilizadas pela professora titular da disciplina) das 
aulas, entrevista semiestruturada oral gravada em áudio, sessão de visionamento e notas de campo com dez alunos com idade variando entre 19 a 32 anos, e a professora titular da disciplina. A referida professora formou-se em Letras/Inglês pela mesma universidade na qual leciona, possui 35 anos de idade, e uma experiência docente na universidade que ultrapassa os quinze anos. Sua principal área de interesse concentra-se na formação do professor leitor em língua inglesa.

É válido ressaltar ainda que os participantes e a professora envolveram-se como atores sociais em todas as etapas da coleta de dados e o pesquisador não era a professora titular da disciplina, sendo observador não participante da mesma.

Quanto às sessões de visionamento, elas foram realizadas com a professora e com os alunos da turma individualmente, com o intuito de evidenciar as impressões dos sujeitos sobre seu processo de atuação em sala de aula, não sendo parte da disciplina em questão. É importante destacar também que, no momento do visionamento, cada participante teve acesso ao seu vídeo apenas, não sendo possível observar o do outro, uma vez que o mesmo possibilita criar a oportunidade para que alunos e professores externalizem seus pensamentos e interpretações sobre suas próprias ações.

Uma análise qualitativa dos dados destacou os tipos de correções que eram providas aos participantes a partir da interação oral em sala de aula, sendo que foi analisado o feedback corretivo oral fornecido pela professora (ou pelo aluno/colega) nos momentos de interação oral em sala de aula, do ponto de vista da teoria sociocultural, a partir da triangulação dos dados, com base em diferentes tipos de feedback corretivo.

\section{Os resultados do estudo}

A interação entre a professora, os aprendizes e entre os pares foi observada e analisada por meio de excertos, indo ao encontro dos pressupostos teóricos abordados ao longo do artigo, por envolverem questões tanto de cunho colaborativo assim como interativo e comunicativo do aprendiz com a professora e com os colegas em contextos sociais.

Assim, nesta seção, os dados coletados com os futuros professores de inglês são descritos, interpretados e analisados, a partir das categorias de análise expostas no quadro a seguir, que foram redefinidas e exemplificadas a partir de Lyster e Ranta (1997) e Ranta e Lyster (2007).

Quadro 1

Categorias de análise dos dados

\begin{tabular}{|l|}
\hline Frase contendo o erro ou a inadequação: “She has baby" \\
\hline Reformulações: o interlocutor fornece a resposta correta. \\
\hline $\begin{array}{l}\text { Recast: reformular o enunciado do aprendiz na língua-alvo, com sutileza e sem ênfase, sem } \\
\text { indicar explicitamente o que está errado. Ex.: "A baby" }\end{array}$ \\
\hline $\begin{array}{l}\text { Correção Explícita: fornecer uma informação adicional ao erro do aprendiz, indicando } \\
\text { claramente que o que o aluno disse está impreciso. Ex.: "No, you should say: a baby" }\end{array}$ \\
\hline Prompts: o interlocutor não fornece a resposta correta. \\
\hline $\begin{array}{l}\text { Pedidos de Esclarecimento: pedir por esclarecimento sobre o enunciado do aprendiz, } \\
\text { esperando que ele reestruture o mesmo. Ex.: "Sorry?"; "Pardon?" }\end{array}$ \\
\hline $\begin{array}{l}\text { Feedback. Metalinguístico: fornecer comentários, informações linguísticas ou perguntas } \\
\text { relacionadas ao enunciado malformado do aprendiz a fim de que ele possa se autocorrigir. }\end{array}$ \\
\hline
\end{tabular}


Ex.: "You need an indefinite article"

Elicitação: solicitar a forma correta e levar o aprendiz à autocorreção por meio do uso de perguntas para que o aprendiz possa completar a forma correta. Ex.: "She has...?"

Repetição: isolar a frase errada em um tom interrogativo ou exclamativo, esperando a correção do enunciado por parte do aprendiz. Ex.: "She has baby?"

Fonte: Elaborado pela primeira autora do artigo.

Primeiramente, os dados foram quantificados a partir da detecção dos turnos e momentos de correção em torno do feedback corretivo oral em cada uma das aulas. Salientamos que foram transcritos somente os momentos das aulas em que o mediador (professor e/ou colega) corrigia os erros dos aprendizes. Assim, foram quantificados 247 turnos e 48 momentos de interação em torno do feedback corretivo oral (48 excertos corrigidos pela professora ${ }^{3}$ ). É válido salientar que quase todos os turnos com erro receberam algum tipo de correção pela professora. Embora tenha havido erro, a professora deixou de corrigir 22 momentos de interação, o que corresponde a 113 turnos nos quais a correção não foi realizada. Os erros que não foram corrigidos pela professora dizem respeito principalmente à pronúncia na língua-alvo.

A partir dos dados coletados, foram detectados 247 turnos e 48 momentos de interação em torno do feedback corretivo oral, ou seja, 48 excertos corrigidos pela professora. O tipo de feedback mais utilizado pela professora foi o recast (30), seguido dos prompts (10) e da correção explícita (8). A preferência da professora pelo uso do recast pode ser explicada pelo fato de ele ser um tipo de feedback que reformula o enunciado do aprendiz e não interrompe o fluxo da comunicação de modo agressivo.

Os prompts mais utilizados pela professora foram o feedback metalinguístico (6), seguido da elicitação (4). Os pedidos de esclarecimento e a repetição não foram opções de correção pela professora. A preferência da professora pelo feedback metalinguístico justifica-se por ser um tipo de feedback em que o interlocutor fornece a regra linguística para que o aluno possa reformular o seu enunciado. Os prompts foram subdivididos em categorias por estarem de acordo com os preceitos da teoria sociocultural e com os estudos de Aljaafreh e Lantolf (1994) e de Nassaji e Swain (2000) no que tange ao grau de explicitude (implícito para o mais explícito) do feedback corretivo. Assim, os tipos de erros mais corrigidos pela professora foram os de pronúncia $(50 \%)$ e gramaticais $(50 \%)$, que foram priorizados em detrimento de outros (léxico, conteúdo, discurso).

Observemos um excerto da interação entre a professora e uma aprendiz, que engloba os tipos de feedback mais utilizados pela professora, o recast, e o prompt, seguido de registros da sessão de visionamento realizada com a aprendiz.

Quadro 2: Interação entre a professora e Rafaela ${ }^{4}$

\section{Tipo de feedback: Prompt e Recast}

Participantes: Professora e Rafaela

\footnotetext{
${ }^{3}$ Esse total de turnos apresentados não corresponde ao total de turnos das quinze aulas observadas que, certamente dizem respeito a uma quantidade maior do que aquela apresentada no estudo.

${ }^{4}$ É necessário deixar claro que os nomes dos sujeitos da pesquisa são fictícios.
} 
Rafaela: the singer *sung ... *has sunger a song

Professora: but the singer has or have?

\section{- Prompt (elicitação) -}

Rafaela: have ... the singer has

Professora: $=$ have or has?

\section{- Prompt (elicitação) -}

Rafaela: $=$ the singers is plural?

Professora: $=$ the singers, plural

Rafaela: but the singer is ...

Professora: $=$ one, yes

Rafaela: the singer has *sunger ...

Professora: $=\underline{\text { sung }}$

\section{- Recast -}

Rafaela: the singer has sung *the beautiful song

Professora: $=$ a beautiful song

\section{- Recast -}

Fonte: Elaborado pela primeira autora do artigo.

No excerto, observamos a combinação do recast com o prompt, um tipo de feedback corretivo que oportuniza a reformulação do erro pelo próprio aprendiz, sem que a forma correta seja fornecida diretamente a ele. Essa tarefa diz respeito a uma atividade de revisão sobre determinada estrutura da língua (present perfect), em que os aprendizes estão formulando respostas para uma atividade do livro didático. Ao fornecer uma dessas respostas, Rafaela acaba hesitando com relação à forma verbal, e a professora fornece um prompt, na forma de elicitação, ao fazer uso de uma pergunta para solicitar a reformulação do enunciado à aluna. Rafaela hesita e a professora fornece novamente o mesmo tipo de prompt na ZDP da aluna a fim de mediar o uso da forma correta ainda não internalizada por Rafaela.

A aluna segue testando hipóteses sobre o uso do has ou do have e, quando ela se apropria da forma correta, acaba cometendo outro erro com relação ao verbo no particípio (sunger). Nesse momento, a professora opta por corrigir a aluna fazendo uso do recast, fornecendo a forma correta à Rafaela, que tenta completar a frase, mas comete novamente um erro ao adicionar the antes de beautiful song. Mais uma vez, a professora fornece o recast à aluna e a interação termina assim, sem uma resposta de Rafaela ou qualquer outro tipo de interação entre a aluna e a professora.

Esse excerto sugere que, ao fornecer feedback corretivo na forma de prompt, a professora cria, intuitivamente, condições para o desenvolvimento e a transformação da resposta (THORNE; TASKER, 2011) de Rafaela, possibilitando a construção conjunta da ZDP da aluna (LANTOLF, 2006), apesar de a professora não ter informação sobre a teoria sociocultural. No entanto, ao final da interação, a professora acaba alterando o padrão da 
correção, ao fornecer o feedback na forma de recast (resposta correta) para a aluna. A princípio, parece-nos que Rafaela se apropria das correções fornecidas pela professora e caminha em direção ao controle independente sobre a estrutura do present perfect. Todavia, por meio da análise desse excerto, não podemos corroborar precisamente se houve internalização ou não (ALJAAFREH; LANTOLF, 1994).

No visionamento com Rafaela, a aluna afirma que estava certa com relação à forma verbal, porém relata que ficou na dúvida ao ser questionada pela professora acerca do uso de has ou have e do aspecto formal e/ou informal da língua inglesa. Ela ainda menciona que a professora queria uma frase completa, mais formal, parecendo ignorar os erros que foram cometidos por ela e a correção recebida. Observamos que, apesar de ela ter incorporado a correção do verbo to sing, ela parece não perceber os erros cometidos durante a interação, que, como no caso de sunger, talvez pudessem comprometer a comunicação da aluna. Acreditamos que o processo de correção de erros orais é complexo, depende do tipo de mediação que é fornecida por outros indivíduos (ALJAAFREH; LANTOLF, 1994) e da capacidade de resposta do aprendiz ao feedback corretivo recebido.

Quadro 3: Visionamento com a Rafaela

\section{Visionamento com a Rafaela}

Rafaela: aqui foi o melhor.

Pesquisadora: aqui, a professora acaba te desafiando a dizer a forma correta, não é?

Rafaela: é, porque eu não lembro se eu tinha falado have ou has, daí eu não lembro o que ela falou direito, mas era mais ou menos assim: eu falei, ela falou, daí eu fui dizer uma coisa, quer dizer, a mesma coisa na frase, tentando ajeitar, mas eu nem sei se eu precisava ajeitar, porque eu achei que eu tava certa, na realidade. Mas eu fiquei pensando ((risos)).

((Continuação do vídeo - Rafaela assiste e dá algumas risadas sobre o que ela vê. Fica um pouco tímida))

Rafaela: a frase tava certa, mas a professora pediu a frase completa porque ela queria que eu fizesse uma frase mais ajeitadinha, mais formal. Eu acho que ela pede esse tipo de coisa para a gente saber que existem formas mais apropriadas para fazer a pergunta ou formar a frase. Que nem, ali era uma coisa mais informal ... tem as perguntas mais formais e mais informais.

Fonte: Elaborado pela primeira autora do artigo.

Ao verificarmos os dados (coletados e transcritos) a partir da entrevista oral realizada com a professora ao longo das aulas ${ }^{5}$, percebemos que há uma regularidade nas formas de correção que ela realiza, principalmente pelo uso mais frequente do recast, pois parece que ela está preocupada em não constranger a aprendiz com o feedback e com o resultado da correção, auxiliando-a sempre que possível. No entanto, percebemos alguns momentos em que o feedback corretivo assumiu a forma de mediação na ZDP da aprendiz, com o intuito de promover desenvolvimento (ALJAAFREH; LANTOLF, 1994), como no caso específico dos prompts. O uso de prompts promove uma mudança na qualidade da mediação, fornecendo à aprendiz o mínimo de assistência necessária para a construção da ZDP.

${ }^{5}$ Visão do pesquisador a partir da entrevista oral realizada com a professora. 
No excerto seguinte, temos uma interação entre a professora, Alice e Paula, em que observamos os prompts (feedback metalinguístico) fornecidos pela professora para que Alice construa a resposta correta à pergunta: When did you eat Japanese food?, pois o tópico da aula naquele dia era uma revisão sobre o passado simples (simple past) e o presente perfeito (present perfect). A professora estava revisando esses aspectos gramaticais, por meio de perguntas orais aos aprendizes, para o teste que ocorreria na semana seguinte. Antes de fornecer a resposta, Alice questiona se é preciso responder com uma resposta completa ou não, antecipando uma possível correção da professora.

A professora fornece a resposta, confirmando que prefere a frase completa. Para isso, ela faz uso de duas informações, uma em inglês e a outra em português, para que a aluna compreenda a mediação fornecida por ela (LANTOLF; POEHNER, 2011), na forma de prompt (feedback metalinguístico), sobre o enunciado em questão. Como Alice possui um bom entendimento da língua, cremos que somente uma informação já seria suficiente para a compreensão. Alice começa a testar hipóteses, hesitando um pouco com relação à forma gramatical. Nesse momento, a professora interfere fazendo uso novamente da língua materna para mediar a interação com a Alice. Percebemos que a mesma não fornece o tempo necessário para que a aluna possa concluir seu raciocínio. Na sequência, a professora fornece outra vez um prompt (feedback metalinguístico), questionando Alice acerca do passado do verbo eat (comer), novamente sem oportunizar o tempo adequado para a resposta da aluna.

Percebendo a interação entre Alice e a professora, Paula prontamente fornece a forma correta do verbo com o intuito de orientar Alice para a resposta desejada. Mais uma vez a professora interfere de maneira direta, repetindo a forma correta do verbo, enquanto Alice observa a interação. Finalmente, Alice fornece a resposta correta e desejada pela professora. A professora aproveita o momento para falar sobre a diferença entre os dois tempos verbais, com o intuito de que toda a turma possa beneficiar-se da explicação fornecida por ela. Ao final da interação, Alice concorda positivamente com a cabeça e a professora dá andamento à atividade.

O excerto analisado fornece-nos indícios de que a professora quer auxiliar a aluna a progredir na LE, mas não é exatamente o que acontece quando ela não oportuniza o tempo necessário para que a aluna reflita sobre a língua. Lantolf e Poehner (2011) afirmam que o tipo de mediação requerida pelos aprendizes varia de acordo com a necessidade deles, porém parece-nos que isso não foi o que aconteceu nessa interação especificamente.

Quadro 4: Interação entre a professora, Alice e Paula

\section{Tipo de feedback: Prompt}

Participantes: Professora, Alice e Paula

Professora: so, Alice when did you eat Japanese food?

Alice: the complete or just ... last month ((Alice quer saber se precisa dar a resposta completa ou não))

Professora: =try to say all the sentence. How can you say in English "eu comi 
comida Japonesa mês passado?”

\section{- Prompt (feedback metalinguístico) -}

Alice: I *have eat ... no ...

Professora: =tu vai dizer mês passado. E aí, hein? Como é que a gente tem que construir a frase?

Professora: ... what is the past of eat?

Paula: $=$ ate

\section{- Prompt (feedback metalinguístico) -}

Professora: $=$ the simple past $\ldots$ so I ate ...

Alice: I ate Japanese food last month

Professora: all right? So, as you have the expression last month, you have to use the simple past and the past of eat is ate and the past participle is eaten. But, remember, you are just going to use the past participle when you use the present perfect. Ok?

Alice: ((concorda positivamente com a cabeça))

Fonte: Elaborado pela primeira autora do artigo.

Como veremos abaixo, na visão de Alice, ela sabia o que responder, pois queria usar o present perfect em sua resposta. Quando começou a falar, parece que ela percebeu que deveria utilizar o passado simples e então ficou na dúvida. Mesmo assim, ela afirma que se tivesse dito I have eaten, teria acertado o verbo. Percebemos que muitas das suas dúvidas se dão pelo medo que ela possui de falar em sala de aula. Alice afirma ter medo do julgamento da professora, e isso acaba, indiretamente, ocasionando o erro. Casos como o de Alice, em que ela possui medo da opinião da professora, podem comprometer seu desempenho linguístico, pois esse sentimento possivelmente gera um bloqueio para o seu desenvolvimento pela ZDP (LANTOLF; POEHNER, 2011). Cremos que o fato de a professora não oportunizar o tempo necessário e o tipo de mediação adequada para que Alice reflita sobre a questão e consiga formular a sua resposta, também acaba gerando um sentimento negativo na aluna e um desempenho insatisfatório na língua, por mais que ela tenha chegado à resposta correta ao final da interação.

Quadro 5: Visionamento com a Alice

\section{Visionamento com a Alice}

Alice: -I have eaten. Eu tinha a frase na minha cabeça, mas aí quando eu comecei a falar eu fiquei pensando se estaria certo, aí eu comecei a falar e aí na outra frase tinha que ser o-ate. Se eu tivesse dito -I have eaten, eu tinha acertado o verbo.

Pesquisadora: você sempre faz esse raciocínio antes de falar?

Alice: sim, por isso que eu me embanano toda. Eu tenho que seguir mais o que eu primeiro penso e parar de pensar assim desse jeito. Se eu acho que é certo eu tenho que falar e parar de ficar com medo do que o professor vai achar. Eu sempre fico com medo do que ele vai pensar, daí eu acabo mudando, mas eu sempre erro por pensar 
demais.

Pesquisadora: mas as correções da professora acabam te auxiliando de alguma maneira?

Alice: sim, porque depois eu acabo olhando e vejo que não, tá certo assim. Às vezes eu saio um pouco fora daquilo que realmente era para falar.

Fonte: Elaborado pela primeira autora do artigo.

Observamos também que nem todo o tipo de feedback e assistência fornecida pela professora caracteriza-se como mediação. A mediação é sensível à ZDP e tem como objetivo o desenvolvimento do aprendiz, e não apenas a resolução de determinada tarefa (LANTOLF; POEHNER, 2011). O professor pode, por exemplo, apontar áreas problemáticas aos aprendizes e sugerir maneiras de evoluir, porém o feedback e o auxílio só serão úteis se os aprendizes forem capazes de responder a eles de um modo que reconheçam e compreendam o auxílio recebido.

Assim, cremos que a correção de erros precisa ser vista como um processo, um diagnóstico das habilidades dos aprendizes e de até onde eles podem chegar com o modo de mediação apropriada. Para isso, é necessário perceber o nível de desenvolvimento potencial dos alunos e fornecer a forma de mediação adequada por meio do diálogo colaborativo entre os envolvidos nesse processo, determinando o que o aprendiz já sabe, para que se possa ensinar de acordo com aquilo que ele realmente necessita saber, oferecendo-lhe uma situação de aprendizagem frente ao tópico desejado. O nível de desenvolvimento potencial dos aprendizes pode ser determinado através da solução de atividades realizadas sob a orientação de um especialista ou em cooperação com colegas mais experientes em sala de aula. Nesse caso, o professor atua como um guia do processo cognitivo até o momento em que o aprendiz tenha condições de assumir o controle sobre sua própria aprendizagem. Isso implica em assistir o aprendiz para que ele seja capaz de ir além do que ele poderia sem auxílio.

Em se tratando de ensino-aprendizagem de LE, a qualidade e o tipo da mediação oferecida pelo DA aos aprendizes é essencial para promover o desenvolvimento na LE, uma vez que se pretende interpretar corretamente e auxiliar os aprendizes a expandir seus potenciais de aprendizagem (LANTOLF; POEHNER, 2004). Com base nisso, alguns princípios são indispensáveis para o DA na sala de aula de LE: fornecer o suporte necessário para o desenvolvimento do aprendiz; a mediação precisa ser adequada às necessidades dos aprendizes; a interação deve ocorrer em torno da ZDP e ser desafiadora aos alunos; e o desenvolvimento da LE precisa envolver a internalização do conhecimento teórico (POEHNER, 2008).

Ressaltamos ainda que o DA precisa ser adaptado ao contexto de ensino-aprendizagem investigado, em que o auxílio é fornecido aos aprendizes de modo graduado e contingente, resultando no desenvolvimento dos mesmos. Isso não ocorreu na sala de aula pesquisada, possivelmente pela falta de formação da professora na área, embora ela tenha levado em consideração as individualidades de cada aprendiz ao realizar a correção dos erros orais, como ela mesma declarou no momento da entrevista com a pesquisadora.

Os resultados sugerem que a correção de erros orais é importante no sentido de promover o ensino-aprendizagem na sala de aula de LE e favorecer a formação do futuro professor de inglês. A correção precisa ser realizada como um processo, e com base em uma teoria do desenvolvimento humano, levando em consideração os fatores linguísticos, cognitivos e idiossincráticos de cada aprendiz. Partimos ainda da premissa de que o conhecimento é construído socialmente, e que o feedback fornecido na interação pode facilitar o desenvolvimento do aprendiz, e contribuir para a sua formação como professor de LE (LANTOLF; THORNE, 2006). Nesse sentido, propomos uma escala regulatória para o 
feedback oral a ser adaptada e utilizada pelos professores em sala de aula, com base nos estudos de Aljaafreh e Lantolf (1994) e de Nassaji e Swain (2000), como uma forma de aliar o feedback corretivo, o DA e a ZDP de forma processual.

Quadro 6: Escala Regulatória para o feedback corretivo oral

\begin{tabular}{|c|c|c|}
\hline 0 & Pausa & Implícito \\
\hline 1 & $\begin{array}{l}\text { Mostrar ao aluno que o enunciado não foi compreendido. } \\
\text { (Pardon? I don't understand!) }\end{array}$ & \\
\hline 2 & Solicitar que o enunciado seja concluído. & \\
\hline 3 & $\begin{array}{l}\text { Indicar que há algo errado com a frase. } \\
\text { (Is there anything wrong in this sentence?) }\end{array}$ & \\
\hline 4 & $\begin{array}{l}\text { Assinalar a palavra errada. } \\
\text { (There is a problem with the word } X ; \text { What's the past of the verb W? }\end{array}$ & \\
\hline 5 & Explicar o motivo do erro. & \\
\hline 6 & Fornecer a resposta correta. & \\
\hline 7 & Fornecer exemplos sobre a forma correta. & Explícito \\
\hline
\end{tabular}

Fonte: Elaborado pela primeira autora do artigo.

Ao propor a escala regulatória como um fio condutor para a correção e facilitador da mesma na sala de aula pelo professor, estamos partindo da premissa de que não há um tipo de feedback corretivo que seja ideal, pois isso pode variar de acordo com as necessidades de cada aprendiz e das estruturas linguísticas abordadas em sala de aula (AMMAR; SPADA, 2006).

Nesse sentido, evidenciamos a importância de haver um diagnóstico dos níveis de controle que os alunos possuem sobre certas estruturas da língua e de que tipo de mediação carecem, seja um auxílio mais implícito ou mais explícito para seu desenvolvimento na LE, uma vez que os aprendizes podem vir a depender por mais ou menos tempo da regulação do mediador (professor) até atingir o processo de autorregulação na LE.

\section{CONSIDERAÇÕES FINAIS}

Ao analisarmos os dados referentes à correção dos erros orais em sala de aula e o desenvolvimento potencial dos aprendizes, pudemos refletir acerca da importância da correção oral, aliada ao desenvolvimento, levando em consideração os desdobramentos de uma intervenção dialógica e a formação de futuros professores de LE. Nesse sentido, procuramos responder aos seguintes questionamentos: Quais tipos de correção referentes à produção oral dos aprendizes são providas aos alunos pela professora? Como o feedback corretivo se relaciona ao processo de ensino-aprendizagem dos alunos?

Assim, verificamos que a correção faz parte do processo de qualquer aprendizagem, e permite que os aprendizes evoluam na resolução de tarefas, promovendo o desenvolvimento e 
o crescimento dos mesmos. Em sala de aula, a postura do professor perante o erro pode influenciar como o aprendiz percebe esse processo. Para tanto, seria interessante o professor fazer uso de formas de correção de maneira graduada e contingente, que envolvam os prompts da maneira mais implícita para a mais explícita, pois percebemos que, apesar de o recast ser a correção mais utilizada pela professora, ela não leva a uma reflexão e reformulação do erro por parte do próprio aprendiz e para novos entendimentos sobre o erro.

Os resultados das análises apontam para o fato de que o DA poderia ser adaptado e utilizado nas salas de aula de LE, por nos permitir diagnosticar os diferentes níveis de controle que os alunos possuem sobre certas estruturas da língua e de que tipo de mediação eles carecem, sendo que alguns necessitam de um auxílio mais explícito do que os outros para conseguirem se desenvolver na LE (LANTOLF; POEHNER, 2004).

Além disso, salientamos a necessidade de propor a correção de uma maneira diferenciada, e a possibilidade de trabalhar com o feedback corretivo a partir de uma perspectiva teórica, como no caso da teoria sociocultural (ZDP), aliada ao dynamic assessment, que compreendemos como fundamental para o contexto de ensino-aprendizagem de LE e para a formação de futuros professores de inglês, que se utilizam da correção como uma maneira de instrução a fim de promover o desenvolvimento e o aprimoramento linguístico dos aprendizes.

\section{REFERÊNCIAS BIBLIOGRÁFICAS}

ALJAAFREH, A.; LANTOLF, J. P. Negative feedback as regulation and second language learning in the Zone of Proximal Development. Modern Language Journal, v. 78, p. 465-483, 1994.

AMMAR, A. ; SPADA, N. One size fits all? Recasts, prompts and L2 learning. Studies in Second Language Acquisition, 28, p. 543-574, 2006.

BODROVA, E.; LEONG, D. J. Tools of the mind: The Vygotskian approach to early childhood education (2 ed.). Columbus, OH: Merrill/Prentice Hall, 2007.

BORBA, F. R.; LIMA, M. S. O professor de língua estrangeira e sua visão do tratamento do erro. In: ROT'TAVA, L.; LIMA, M. S. (Org.). Linguística Aplicada: relacionando teoria e prática no ensino de línguas. Ijuí: Unijuí, 2004, p. 265-279.

BURNS, A. Collaborative Action Research for English Language Teachers. Cambridge: Cambridge University Press, 1999.

DAVIN, K. J. Integration of dynamic assessment and instructional conversations to promote development and improve assessment in the language classroom. Language Teaching Research, 17(3), p. 303-322, 2013.

ELLIS, R. Corrective Feedback and Teacher Development. L2 Journal, v. I, p. 3-18, 2009.

ERICKSON, F. Qualitative methods in research on teaching. In: WITTROCK, M. (Ed.). Handbook of Research on Teaching. New York: Macmillan, 1986, p. 119-161.

HALL, J. K. Methods for teaching foreign languages. Columbus, Ohio: Merril Prentice, 2001. 
LANTOLF, J. P. Sociocultural theory and second language learning: state of the art. Studies in Second Language Acquisition, 28, p. 67-109, 2006.

LANTOLF, J. P.; POEHNER, M. E. Dynamic assessment: Bringing the past in to the future. Journal of Applied Linguistics, v. 1, p. 49-74, 2004.

. Sociocultural theory and the teaching of second languages. London: Equinox, p. 57-86, 2008.

Dynamic assessment in the foreign language classroom: a teacher's guide. Second Edition. University Park: CALPER Publications, 2011.

LANTOLF, J. P.; THORNE, S. L. The Sociogenesis of Second Language Development. Oxford: Oxford University Press, 2006.

LIDZ, C. S. Practitioner's guide to dynamic assessment. New York: Guilford, 1991.

LURIA, A. R. Study of the abnormal child. American Journal of Orthopsychiatry, 31, p. 1-16, 1961.

LYSTER, R. Negotiation of Form, Recasts, and Explicit Correction in Relation to Error Types and Learner Repair in Immersion Classrooms. Language Learning, 51, p. 265-301, 2001.

- Differential effects of prompts and recasts in form-focused instruction. Studies in Second Language Acquisition, v. 26, p. 399-432, 2004.

LYSTER, R.; RANTA, L. Corrective feedback and learner uptake negotiation of form in communicative classroom. Studies in Second Language Acquisition (SSLA), v. 19, p. 37-66, 1997.

MITCHELL, R.; MYLES, F.; MARDSEN, E. Second language learning theories. 3rd ed. New York/London: Routledge, 2013.

NASSAJI, H.; SWAIN, M. A Vygotskian perspective on corrective feedback in L2: the effect of random versus negotiated help in the learning of English articles. Language Awareness, v. 8, p. 34-51, 2000.

PANAHI, P.; BIRJANDI, P.; AZABDAFTARI, B. Toward a sociocultural approach to feedback provision in L2 writing classrooms: the alignment of dynamic assessment and teacher error feedback. Language Testing in Asia, p. 3-13, 2013.

POEHNER, M. Dynamic Assessment: A Vygotskian approach to understanding and promoting second language development. Berlin: Springer Publishing, 2008.

Group dynamic assessment: Mediation for the L2 classroom. TESOL Quarterly, 43, p. 471-91, 2009.

RANTA, L.; LYSTER, R. A cognitive approach to improving immersion students' oral language abilities: the awareness-practice-feedback sequence. In: DEKEYSER, R. (Ed.). Practice 
in a second language: Perspectives from applied linguistics and cognitive psychology. Cambridge: Cambridge University Press, 2007, p. 141-160.

SWAIN, M.; KINNEAR, P.; STEINMAN, L. Sociocultural Theory in Second Language Education: An Introduction Through Narratives, 2011.

THORNE, S. L.; TASKER, T. Sociocultural theory and cultural-historical theories of language development. In: SIMPSON, J. The Routledge Handbook of Applied Linguistics. New York: Routledge, 2011, p. 487-500.

VYGOTSKY. L. S. Mind in society: the development of higher psychological processes. Cambridge, MA: Havard University Press, 1978. . Thought and Language. Cambridge: MIT Press, 1986.

WERTSCH, J. V. Mediation. In: DANIELS, H.; COLE, M.; WERTSCH, J. V. (Ed.). The Cambridge Companion to Vygotsky. Cambridge: Cambridge University Press, 2007, p. 178-192.

Recebido em 08/01/2017

Aceito em 19/04/2017

Publicado em 03/05/2017 